\title{
Design Considerations in Designing Age-Friendly Streets
}

\author{
Abraham George* \\ Department of Architecture and Regional Planning, Indian Institute of Technology Kharagpur, India
}

*Corresponding author: Abraham George, Department of Architecture and Regional Planning, Indian Institute of Technology Kharagpur, West Bengal, Pin-721302, India

Submission: 眥 October 03, 2017; Published: 㘹 December 22, 2017

\begin{abstract}
The phenomenon of ageing is a growing concern over the entire world which calls for urgent study, analysis and developing means for mitigation of its ill effects in the future, especially in cities. Overcoming elderly population's needs, problems and providing them acceptable living environment is a major challenge for the societies in the present and future centuries when the growth of the elderly population is predicted to be almost $25-30 \%$ by 2020. Although every country is facing the problems of ageing, most countries are far behind in providing adequate support facilities for elderly to achieve a good quality of life. The study critically examines the 'inconvenience factors' that are related to access and transport that are of prime concern for the age-friendly street design. The 'inconvenience factors' of travel faced by elderly in various case studies are critically evaluated and these are listed and categorized into three categories to facilitate analyzing and understanding the relation among these categories at various levels. Further, 'inconvenience encountered' in relation to 'pedestrian infrastructure', 'public transport systems' and those related to their 'physical and psychological aspects' are classified into subcategories. Through the study, it is found that streets pose serious challenges and obstacles and are problematic for the elderly. It is also found that there exists a relation between 'physical and psychological factors' and 'design and maintenance' of pedestrian infrastructure to facilitate convenience for their access and use which could be reflected in terms of a proposed 'Convenience Index'.
\end{abstract}

Keywords: Age-friendly; Mobility; Inconvenience factors; Convenience index

\section{Introduction}

Population aging' is a global issue in the present era and which has a direct impact on the quality of life, self-reliance, health care and social welfare systems for the elderly. The increase in elderly population is happening due to the result of low birth rates and extended longevity achieved through the developments in health care and medical assistance. This is supported by various welfare schemes which made a notable change in the ratio of the newly born to elderly with the age of 60 years and above. The globally aged population began increasing during the end of the twentieth century and consistently maintaining the trend due to the availability of improved medical facilities which is one of the major reasons Palacios et al. [1]. During the mid-Twentieth Century ageing phenomenon is predominantly observed in developed countries, later on, it appeared in developing countries causing significant after-effects. Although there are differences in determining what should be the age limit for deciding whether elderly or not, UN has accepted 60 years as the bar WHO [2]. Overall global figures show that population of above 65 years was 500 million people during 2006 and it is expected to increase by 2 billion people by 2050 , the expected increase in developing countries is about $80 \%$ by 2050 National Institute on Aging [3]. India has around 100 million elderly and the number is expected to increase to 323 million by
2050 , which will contribute to $20 \%$ of 2050 s population of India Help Age India [4].

India witnessed a rapid increase in population during 2001 and 2011which is seen recently as demographic transition due to increasing migration of people to cities. Studies reveal that presently more than $31 \%$ Indians are living in urban areas Census of India [5]. At the same time, the elderly population is also growing rapidly in numbers, which adds up to multiple concerns regarding their quality of life. Elderly have certain needs to ease their daily life and appropriate planning has to be done by considering their needs. Elderly need a quality living environment which will facilitate creating positive social networks among them. There are many factors that affect elderly population beyond health care which is important to be carefully planned for their satisfaction, and equal societal participation Kalache A [6].

Achieving Quality of life for elderly people mainly depend on their participation in society and self-sufficiency in all respects. Accessibility to infrastructure facilities, information, health care, and safety and security systems that is central to the empowerment of the elderly to have confidence and participation in the society. The majorities of Indian cities are poor in access to information, public transport systems and built environment for age-friendly 
design. In order to bring the change in the present systems, making planning and design initiatives focused in the direction of 'agefriendly; people of all ages which include elderly also' is highly essential to all cities. Problems related to age-friendliness are seen in different areas, such as outdoor and built environment, transportation, social participation, housing, health services and community support, communication and information, employment and finally in 'respect and social inclusion' WHO [7].

The study is focused on 'inconvenience factors' related to 'access and transportation' and 'physical and psychological factors' concerning the elderly in particular. A listing of inconveniences is done to analyze the age-friendliness of infrastructure facilities and finding the correlation among the inconvenience factors and the 'physical and psychological' factors and 'design and maintenance'. This will help to develop an age-friendly design that can support elderly. 'Access and transportation' factors are sub categorized into two; pedestrian infrastructure and public transportation systems, and problems related to physical conditions of elderly are extracted from various case studies. The importance of psychological factors of elderly is considered to understand the 'response of elderly to available infrastructure'. Further, these are used to generate acceptable designs for all ages, especially for the elderly.

\section{Ageing and Mobility}

Mobility is the critical ability for social integration in a complex urban society Irwin N [8]. Elderly are less likely to travel than other age groups which are due to their lowered mobility and access to transport. They usually prefer to walk which makes it a key concern in providing a link for them with the social and recreational spaces. The absence of sidewalks, inadequate time to cross the roads, lack of resting areas and unmarked intersections are significant challenges for elderly people and differently-abled people irrespective of age group. Lack of safe and enabling spaces compels elderly to struggle walking to fulfil their daily needs Kevin De Good [9]. Walking and public transport are preferred travel modes of elderly, but the inconveniences encountered result in a drop in their use. A US study by National Centre for Health Statistics reported that 'barriers in pedestrian environment' tend to make $75 \%$ of elderly to avoid walking outdoors Rosenbloom S [10]. Such hurdles and challenges pose negative implication on their healthy life, social and mental wellbeing.

Elderly have their own physical constraints that make travel difficult for them. Problems of vision, lowered ability to sense movement, spatial cognition, and visual access to information displays are the some of these constraints. Mobility is not only travelling to a destination, but elderly do care about their safety, security, and comfort. Most of the streets are designed for the anthropometrics and ergonomics of normal people, which make it difficult for the elderly or differently-abled. Once these problems are taken care of, the designs and facilities become nearer to agefriendly designs that are good for all age groups.

\section{Understanding Inconvenience Factors}

Focusing on the use of the public and private streets by the elderly; their problems and challenges faced on streets will constitute the development of 'convenience factors'. It is necessary to investigate and identify inconveniences and challenges that are faced by the elderly. Inconveniences occur due to the improper design and maintenance of mobility facilities and challenges due to variations in the different degree of disabilities. While a cataractaffected person requires no bright ambient light conditions, the visually impaired will require bright light conditions. In spite of all hurdles and inconveniences streets and pathways are commonly used by the elderly along with another public opens spaces like parks and community spaces. Streets connect them with recreational, social and other activities and facilitate their social participation that contributes to their wellbeing. A study in San Antonio reveals that elderly people without a car are more likely to walk and they have health benefits are the goodness of walking Carp FM [11].

Inconvenience factors and subcategories are shown in Figure 1. Inconveniences factors include access and transportation, and it has different subsections. 'Access' is mainly related to streets, pathways, street furniture and information design. The design of the streets and ancillary facilities contribute to the degree of age-friendless of streets and infrastructure. Listing these inconveniences related to pedestrian access and infrastructure will give a basis for assessment and improvement for age-friendliness. Transportation systems begin with the means and mode of access from home through the community to public transportation like bus stations and other supportive infrastructure. It does extend to getting into the bus by the elderly and differently-abled, comfortably seating them till their desired destination and safely lighting for continuing their journey to the destination.

The 'physical and psychological', inconveniences factors consider mainly those factors that are usually encountered during travel by the elderly people. Elders are physically weaker than younger people. The mobility of elderly can be restricted by their physical weakness, thus they move slower than other age groups. Inconveniences also come from their psychological behavior and thinking. Elderly are more conscious about their movement; slow, and safe movements, the weakness of ageing make them react very slowly. Mobility gives them different dimensions other than just travel; psychological, bodily exercise and social involvement by interacting with the local community. Elderly forms the major group of people to experience the benefits of short walking and social gathering compared to other age groups Metz DH [12]. Long distance self-driving is also a problem for elderly since managing such work trips every day makes them uncomfortable. A study in the USA found that elderly people who drive a long time have increased levels and symptoms of depression Marottoli [13]. Better public transport facility and travel related information systems can avoid such avoidable long distance work trips for elderly and when they enjoy their trip it helps to reduce depression. Depression is a common problem among elderly and a recent study by American Psychological Association [14] found that relocation of houses, loss of loved ones and treating the ill partner are causes for increased level of depression. Access can be a key factor in reducing 
depression, and improving access to the recreational facilities helps them to open up new social connections which reduce loneliness and depression. The street is the key element that has a significant influence on psychological factors and comfort of elderly. Elderly prefer more comfortable when the streets are conducive in terms of design, maintenance, lighting, assistance for help and seats along paths. This is to be complimented by deigning to address their psychological factors. Hence, it is important to consider elderly physical and psychological needs along with transport related inconveniences to develop a better design which has higher 'degree of age-friendliness'.

\section{Travel Related Inconveniences}

Travel related inconveniences are subdivided into inconveniences related to pedestrian infrastructure and public transport systems. With the help of various case studies, key issues are identified and from these issues and observations, relevant parameters are identified to 'assess the degree of age-friendliness' and 'develop age-friendly guidelines and standards' for future street designs and improving existing streets and infrastructure.

\section{Inconveniences related to pedestrian infrastructure}

Pedestrian travel has a major share in the mode of transportation and it almost equates in the percentage share of walk trips to motorized trips. According to Census of India 2011, in the top 53 Indian cities with a population of 1 million and above, record a share of $23 \%$ to $57 \%$ of non-motorised work trips Census of India [15]. These figures give an idea as to how much pedestrian facilities are important for a city, in order to carry out the daily walk trips. Elderly are more likely to travel walking than other age groups in which case lack of age-friendliness create problems that affect their safety, security, health and wellbeing. Studies have identified that elderly people face problems on the road because of unavailability of pedestrian pathways WHO [7]. On streets, elderly behave differently than other age groups since they move slowly, are less mobile and with the risk of fall, and they find it difficult to manage crowded situations, Transport for London [16]. Pavement conditions, traffic volume, crossings, and obstructions will complicate usage by elderly and differently-abled (Table 1).

\section{Inconveniences related to public transport infrastructure}

Public transport is one of the preferred modes used by the elderly that requires infrastructure like vehicles, roads, bus shelters and waiting for areas. Congestion at bus stops, lack of information concerning trips and destination, lack of age-friendly buses, access to metro station, difficulty in using wheelchair, inadequate seating in waiting area, safety and security, and availability of help in need like police and medical; by way of blue-light aid poles, are some of the major problems that are faced by the elderly, listed in the Table 2 .

\section{Physical and Psychological Inconveniences of Elderly}

Ageing is an inevitable phase and process in life through which people undergo lack lowering in physical strength and increasing mental stress. Elderly feel difficulty to walk, use public transport and other facilities if the streets, public transport systems, and other facilities are not elderly-friendly. It is also important to consider their psychological needs in the design of infrastructure and modifying already existing facilities to be age-friendly. Psychological inconveniences of elderly are closely related to their physical and mental abilities. As they age, they also degenerate in their ability to identify objects, detect motion, to perceive depth and level differences, colour, touch and feel, various modes of lighting, hearing, even smell and kinaesthetic. A study in the UK found that difficulty in way finding is higher with elderly people, due to lowered ability for spatial cognition Burns P [23], Wilkniss SJ [24]. These problems could be solved with proper path, signage and information design with self-help or assisted. Vision and hearing are the two critical abilities needed for movement; which are affected due to ageing and their vision and hearing capabilities vary with other age groups. Hence, a street with obstructions such as garbage bins, street vendors, and parked vehicles make the movement of elderly more difficult, especially with their lowered vision and hearing. A study found that in elderly people, a vestibular system which helps to maintain balance loses $40 \%$ of its sensory cells by the age 70 years; therefore, they rely on vision to maintain their balance Rosenhall [24]. In complex situations, elderly struggle to negotiate such in spite of their weak physical conditions which adversely affect their psychology and behaviour. Therefore, the risk of an accident is higher, and it is important to include the psychological factors in any age-friendly designs, which is favoured for other age groups too. Table 3 gives the listing of issues of elderly related to psychological inconveniences.

\section{Parameters to be considered for age Friendly Street Design}

Elderly people are the vulnerable group of road users; they face different kinds of inconveniences during travel. Many researchers have investigated and come up with their arguments on safeguarding the elderly from road accidents. Mathey argued for new interventions Mathey [28] and worked out his ideas on giving information to the pedestrians concerning driver's behaviour. Langlois suggested recommendation on reducing travel time, the number of the traffic island and longer crossing time Langlois JA [29]. Studies found that elderly people are less likely to travel by crowded pathways and more likely to go directly to their destinations OECD [30]. Other researchers worked on developing facilities such as rest points and shelter for elderly pedestrians in between residential areas and nearby shops and along frequented routes FEPA [31]. Considering elderly safety on road Hauer recommended 'elderly perspective' to the design of intersections Hauer [32]. Later, researchers started investigating the quality of 'road conditions and roadside environment' while Sarkar proposed an approach to 'evaluate safety'. His evaluation technique included assessments for pedestrian safety, the comfort of road users, conveniences, continuity, system coherence and aesthetics of streets Sarkar [33,34]. In the case of pedestrian crossings Jacob and Willson found that, in London and some towns near to London, elderly preferred to cross the road at pedestrian crossings which prove that elderly place safety first. Pedestrian facilities are complex 
systems that have many sub-systems which facilitate pedestrians. Although pedestrian signals and such supporting facilities at pedestrian crossings are useful, Bailey found that $25 \%$ of elderly had difficulty in seeing signals. Hence for age-friendly street designs, the location of signal and signage with befitting visual ergonomics is a must. Many researchers have emphasised the importance of 'pedestrian refuge' or 'islands for elderly' facilitates crossing long and wide roads by breaking into small tasks which reduce the risk of accidents and associated fear Zegeer [35]. Implementing 'speed limit' in streets is good to reduce accidents since many researchers have stated that 'vehicle speed' is a key factor in pedestrian fatalities. In the case of UK, injury accidents reduced to $64 \%$ and $68 \%$ in the town centre and residential areas respectively, when they reduced the speed from 35 to $20 \mathrm{mph}$ (Promising, 2001). OECD research also recommends a reduction in speed for reduced risk levels in residential and commercial zones OECD [36].

'Quality of walkways' is an important factor that influences elderly-movement. In general, designs are defective with uneven kerbs and surfaces, steepness, abrupt level differences, slippery surfaces, broken slabs, intruding electric poles, tree stumps, potholes and the like. 'Sharing of path' by cyclists and pedestrians pose problems for elderly; risk of accidents is higher since they are physically and psychologically weak. This study establishes that for the elderly, physical and psychological ability and their travel related difficulties are highly correlated. Therefore, these parameters influence the infrastructure designs; reduction in risk of accidents, increasing convenience level and assuring safe, secure and empowered mobility for the elderly.

\section{Parameters of Inconvenience in the Indian Urban Context}

Table 1: Overview of inconveniences faced by elderly in the use of pedestrian facilities.

\begin{tabular}{|c|c|c|}
\hline Issue & Observation/inconvenience & Source \\
\hline Traffic Volume & $\begin{array}{c}\text { High volume at level crossings creates fear in elderly to cross the road. Harsh driving. Silent and high-speed } \\
\text { vehicles. }\end{array}$ & {$[17,18]$} \\
\hline Footpath Availability & $\begin{array}{l}\text { Having footpaths only one side, no footpath for safe walking. Narrow path and overcrowding make walking } \\
\text { difficult. }\end{array}$ & [19] \\
\hline $\begin{array}{l}\text { Footpath Quality and } \\
\text { Compositions }\end{array}$ & $\begin{array}{l}\text { The poor paving condition, use of uneven/broken slabs, bricks or tiles. Broken/unpaved surfaces. Abrupt level } \\
\text { changes, dirt, and sand obstructing safe walk or wheelchair users. }\end{array}$ & {$[7,20]$} \\
\hline Obstructions & $\begin{array}{l}\text { Ill-panned parking, dustbins along paths, Street vendors, with goods spread on the footpath. Broken kerbs, } \\
\text { pillars, and rubbish. Car exit / entry cuts, Cyclists and shared tracks. }\end{array}$ & {$[19,21]$} \\
\hline Crossing Facilities & $\begin{array}{l}\text { Lack of road crossings and road markings. Short time to cross at signalled intersections, escalator/elevator for a } \\
\text { foot over bridges, lack of instruction regarding crossing. Uncontrolled vehicle speed near to the crossing areas. }\end{array}$ & {$[7,18]$} \\
\hline Other Facilities & Footpaths without street lights, community/police aid poles. Footpaths without rest areas; seats and benches. & [7] \\
\hline
\end{tabular}

Table 2: Overview of inconveniences faced by elderly in public transport facilities.

\begin{tabular}{|c|c|c|}
\hline Issue & Observation /inconveniences & Sources \\
\hline Problems of wheelchair and crutches users & Buses without facilities to move wheelchairs inside the bus & [7] \\
\hline Lack of testing facilities in waiting for areas & Deserted waiting areas without proper facilities in shelters & [12] \\
\hline Information about Bus and Routes & Lack of timetable and needed information's on buses for the passengers in the bus & Shaky old buses \\
\hline Vibrations & Seats without handrails, broken seats & [22] \\
\hline Uncomfortable seating & Harsh behaviour from conductors & \\
\hline Behaviour of Conductor & Because of less time older people struggle to board buses \\
\hline Stoppage time of bus in bus stops & & \\
\hline
\end{tabular}

Table 3: Overview of physical and psychological inconveniences of elderly during travel.

\begin{tabular}{|c|c|c|}
\hline Issue & Observation /inconveniences & Source \\
\hline Fear & Crossing roads: Wider roads take more time to cross, Provision of the traffic island to ease the situation. \\
Overcrowded paths, fear of getting lost in the crowd. & [25] \\
\hline Balance & Risk due to slow walking and reaction time, falling, and wheelchair usage is high with deteriorated pavements. & [2,26] \\
\hline Vision & $\begin{array}{c}\text { Lack of street lighting added to impaired vision and light pollution heightens problems of safety and security; } \\
\text { creates loneliness, fear. }\end{array}$ & {$[24]$} \\
\hline Hearing & Risk due to slow reaction time lowered ability to identify objects and obstructions, especially threats. & [27] \\
\hline Boarding Buses & $\begin{array}{c}\text { Difficulty in lifting legs and negotiating heights; higher deck height and rise, non-availability low-floor transport } \\
\text { and hateful treatment of conductors and bus drivers. }\end{array}$ & [10,28] \\
\hline
\end{tabular}


A proposed index indicating as to what extent the inconvenience variables in the environment given in Tables 1-3 influence in making elderly life difficult in the Indian urban context is attempted to be mapped on to Figure 1. As per the Government of India
'Situation Analysis Report' of the Ministry of Statistics and Program Implementation-2011, (P-40), the number of elderly having one or the other disabilities per 100 elderly persons in urban areas is recorded as follows in Table 4.

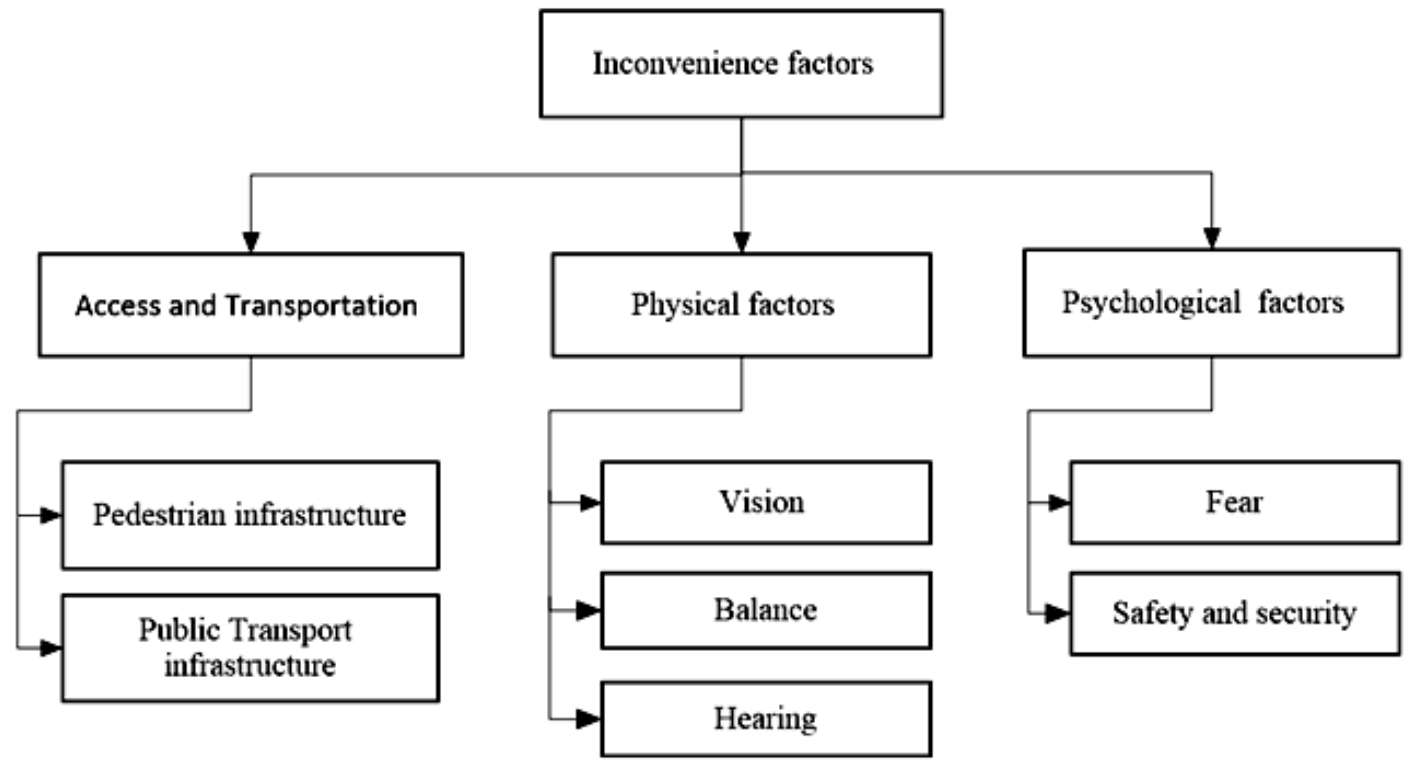

Figure 1: Inconvenience factors and subcategory.

Table 4: Problems faced by the Indian elderly.

\begin{tabular}{|c|c|}
\hline Aspect of consideration & No./100 elderly \\
\hline At least one disability that interferes with mobility & 5.5 persons $/ 100$ elderly \\
\hline Loco motor problems & 2.79 persons $/ 100$ elderly \\
\hline Hearing and Speech disability & 1.5 persons/100 elderly \\
\hline Low Vision \& Blindness & 1.5 persons/100 elderly \\
\hline
\end{tabular}

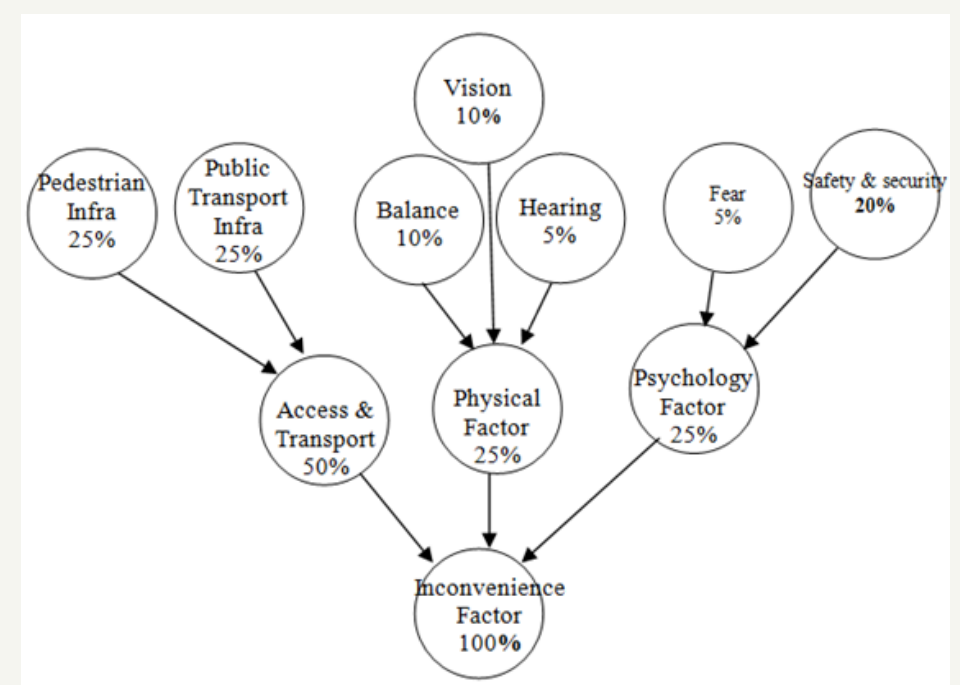

Figure 2: Breakup of factor weight age contributing to inconvenience for calculating a convenience Index for a given street in India. 
Depending on the design of an Indian urban street it can be stated based on Indian statics available that at least 5.5 per 100 of elderly who use the street find it either impossible to navigate or navigate with great difficulty; even when they are assisted. It is, therefore, important to evaluate a street's design for its ability to cause inconvenience to the aged. As a first attempt one can distribute the following weighting indices with base as 1 (Figure 2) to each type of elderly limitations that a street is possibly contributing in making street life for the aged difficult in general. A Street can be evaluated using such indices. The relative weight that is proposed in Figure 1 arrives at as posts and is derived based on the following reasons.

Both poor pedestrian infrastructure; kerbs, foot-paths, level differences etc, and poor public transport infrastructure; bus stops, locations, levels, etc, in terms of their non-friendly designs are equally responsible as contributing agents to inconvenience. As a first estimate, they can be stated to contribute not less than $25 \%$ each in creating inconvenience situation for elders, thereby summing of to $50 \%$ of the reasons why elders perceive these their problems of old age mobility when using Indian streets.

Physical factors such as 'poor vision' and 'poor balancing ability' are observed to be more widespread than the hearing loss in Indian geriatric population. They have been estimated at $10 \%$ each. The sum total that elderly person's physical factors contribute to inconvenience is limited to $25 \%$ as all aged population has lower physical functioning capabilities as part of the natural aging process. On the contrary, enthusiasm on part of elders to 'remain integrated' with outside public life does not diminish with age.

When existing infrastructure needs to be redesigned or when resources need to be distributed to various categories of refurbishing work on Indian streets, designers and planners need a heuristic or an index that will indicate the degree of emphasis on each factor and sum up to a final Convenience Index. Some streets may have certain features already built in; very unlikely. There is a need to evaluate the existing age-friendly spots on a street that is being taken up, for instance, urban renewal. A street Convenience Index can then be defined in terms of percentage. If a street has zero factors contributing to inconvenience then such a street's CI would be a $100 \%$ age-friendly. Low Convenience Index indicates a highly age-unfriendly street. A given street can be evaluated and multiplied with the weighting proposed in Figure 1 of individual contributors to calculate its convenience index for the elderly [3739].

\section{Conclusion}

Ageing is a global issue and countries need to develop adequate support systems and assistance including pension schemes to the ever increasing ageing population. India is gearing up for urban designs that are smart, and there is a growing need for setting up acceptable age-friendly infrastructure facilities that support all age groups. It is important to consider how to bring smartness to resolve the problems of elderly people along with all other age groups. The study makes clear that incorporating the requirements of elderly lead to age-friendly designs, especially for streets are the connecting veins to their social, recreational interactions. Such age-friendly streets also it plays an important role in keeping the physical strength of the elderly with daily movement and exercise benefits. Elderly people tend to travel less, so the importance of streets in the community is a matter of high priority for elders. Such designs will result in a better degree of age-friendliness with enhanced Convenience Index. Every street, therefore, needs to be evaluated and assigned Convenience Index for age-friendliness. Avoiding the inconvenience factors can improve the street quality, standards and reduce the risk of accidents. The distribution of weight causing inconvenience as per Figure 1 is in the form of a proposal and need to be validated by analysing typical streets in urban India.

\section{References}

1. Palacios R (2002) The future of global ageing. International Journel of Epidemiology 31(4): 786-791.

2. WHO (2007) Global age-friendly cities: A guide.

3. National Institute of Aging. (2007) Why population aging matters: A Global Perspective. Publication No: 07-6134.

4. Help Age India (2015) State of Elderly in India 2014. Help Age India, New Delhi, India.

5. Census of India (2011) Other workers mode and distance of commute trips.

6. Kalache AKI (1997) A global strategy for healthy ageing. World Health 50(4): 4-5.

7. Irwin N (1970) Public Transit and the uality of urban living. Ekistics 29: 47-57.

8. Kevin DeGood (2011) Ageing in place, stuck without options: fixing the mobility crisis threatening the baby boom generation. Transportation for America.

9. Sandra Rosenbloom (2009) Meeting transportation needs in an agingfriendly community. Journal of the American Society on Aging 33(2): 33-43.

10. Carp FM (1971) Pedestrian transportation for retired people. Highway Research Records 356: 105-118.

11. Metz DH (2000) Mobility of older people and their quality of life. Transport Policy 7(2): 149-152.

12. Marottoli RA (1997) Driving cessation and increased depressive symptoms: prospective evidence from the New Haven EPESE. J Am Geriatr Soc 45(2): 202-206.

13. Clay RA (2014) Living with not dying from Alzheimer's (2014).

14. Census of Inida (2011) Population Table.

15. Transport for London (2013) Older pedestrains and road safety.

16. Carp (1997) The older pedestrian in San Francisco. Highway Research Records 403: 18-25.

17. Akash J, Ankit G, Rajat R (2014) Pedestrian crossing behaviour analysis at intersections. International Journal of Traffic and Transport Engineering 4(1): 103-116.

18. ESAF (2013) Walk ability and pedestrian facilities in thrissur city. Thrissur Health Bridge.

19. George Dunbar CA (2004) Road safety research report no. 37, older pedestrians: a critical review of the literature. London: Department for Transport, London. 
20. ITDP (2013) Footpath Design: A guide to Creating Footpaths that are safe, Comfortable, and easy to use. Institute for Transportation \& Development Policy.

21. Buys LS (2011) Transportation behaviours of older adults: an investigation into car dependency in urban Australia. Australian Journal on Ageing 31(3): 181-186.

22. Burns P (1999) Navigation and the mobility of older drivers. J Gerontol B Psychol Sci Soc Sci 54(1): S49-S55.

23. Wilkniss SJ (1997) Age related differences in an ecologically based study of route learning. Psychol Aging 12(2): 372-375

24. Rosenhall U, Rubin W (1975) Degenerative changes in the human vestibular sensory epithelia. Acta Otolaryngol 79(1): 67-81.

25. Promising (2001) Measures for pedestrian safety and mobility: A cross Europe study. The Netherlands. Leidschendam: SWOV Institute for Road Safety Research.

26. Brauer SG, Woollacott M, Shumway-Cook A (2000) The interacting effects of cognitive demand and recovery of postural stability in balanceimpaired elderly persons. J Gerontol A Biol Sci Med Sci 56(8): M89-M96.

27. HAPI (2014) Physiology and psychology of aging, health and place. Health and Places Initiate, Harvard Graduate School of design.

28. Mathey F (1983) Attitudes and behavior of elderly pedestrians. Int J Aging Hum Dev 17(1): 25-28.

29. Langlois JA, Keyl PM, Guralnik JM, Foley DJ, Marottoli RA, et al. (1997) Characteristics of older pedestrians who have difficulty crossing the street. Am J Public Health 87(3): 393-397.

30. OECD (1970) Pedestrian Safety. OECD, Paris.

31. FEPA (1995) Older people on foot. Federation of European Pedestrian, The Hague, Netherlands.

32. Hauer E (1988) The safety of older persons at intersections. Transportation in an Aging Society 2: 194-252.

33. Sarkar S (1993) Determination of service levels for pedestrians with European examples. Transportation Research Records 1405: 35-42.

34. Sarkar S (1995) Evaluation of safety for pedestrians at macro- and micro-levels in urban areas. Transportation Research Records 1502: 105-118.

35.Zegeer CV (1994) Current trends in crashes to older pedestrians and related safety treatments in the United States. Preceedings of the Conference Strategic Highway Program (SHRP), Swedish National Road and Transport Research Institute, Stockholm, Sweden, pp. 53-71.

36. OECD (1986) Effectiveness of Road Safety Education Programmes. OECD, Paris.

37. United Nations (2015) World population Ageing. Department of Economic and Social affairs, New York, USA.

38. Metz D (2000) Mobility of older people and their quality of life. Transport Policy 7: 149-152.

39. Report-Situational Analysis of the Elderly in India, June 2011. Central Statistics Office-Ministry of Statistics \& programme Implementation. 